\title{
Toward an Ecosystemic Approach to Chronic Care Design and Practice in Primary Care
}

Hassan Soubbi, MD, PbD

Department of Family Medicine, Sherbrooke University, Sherbrooke, Quebec, Canada
Conflict of interest: none reported

\section{CORRESPONDING AUTHOR}

Hassan Soubhi, MD, PhD

Sherbrooke University

Unité de Médecine de Famille, 305 St-Vallier

Chicoutimi, Quebec, G7H 5H6, Canada hassan.soubhi@usherbrooke.ca

\begin{abstract}
Despite the increasing prevalence of chronic conditions and multimorbidities, the essential attributes of the structure and delivery of primary care continue to be defined in terms of disease-specific approaches and acute conditions. Effective improvements will require alternative ways of thinking about chronic care design and practice. This essay argues for an ecosystemic understanding of chronic care founded on a communal and a dynamic view of the response of the patient, family, and health professionals to chronic illness. The communal view highlights the cocreative nature of the response to illness and the need to integrate the skills and resources of all the participants; what and how the participants learn in the course of the illness become central to chronic care. The dynamic view draws attention to the unfolding of illness management activities over time and to the need to engage the illness at specific time points or recurring time intervals that have the potential for important change in the experience of the participants. Chronic care would then include design for community, with an emphasis on the patient and family as necessary participants in the health care team. It would also include design for emergent learning and practice whereby health professionals go beyond standardization of care processes to develop new ways to harness the participants' imagination and learn from the changing experience of illness. Health professionals would also learn to cultivate trust, communal engagement, and openness to experimentation that facilitate collective learning, and help sharpen the participants' responsiveness to the emergent.
\end{abstract}

Ann Fam Med 2007;5:263-269. DOI: 10.1370/afm.680.

\section{INTRODUCTION}

The increasing prevalence of chronic conditions and multimorbidities has stimulated numerous efforts to improve chronic care..$^{1-5}$ The essential attributes of the structure and delivery of primary care continue to be defined in terms of acute conditions and disease-specific approaches, however. ${ }^{6}$ Encounters for chronic care are still treated as if they were unique events rather than a continual process of care., ${ }^{4,7}$

The aim of this essay is to suggest an alternative way of thinking about the structure and delivery of chronic care. Its central claim can be summarized as follows: chronic care is what the patient, family members, and health professionals do to achieve specific health outcomes within the evolving opportunities and constraints of chronic illness. Chronic care in this view is an ecosystemic response to illness: a collective and more or less adaptive response of the patient, family, and health professionals to the changing biological and psychosocial manifestations of the illness. In the following sections, I unpack this claim by first reviewing the main features of chronic care activities. Next, I propose 2 perspectives that can help integrate these features into chronic care design and practice. Finally, I discuss implications for chronic care design and present recommendations for clinical practice. 
THE NATURE OF CHRONIC CARE ACTIVITIES Chronic care activities have 2 main characteristics. First, they entail a conceptual shift from disease management to illness management. Disease management refers to clinicians' understandings of the biomedical model of disease progression. ${ }^{8}$ In contrast, illness management refers to how patients, families, and other members of the social community perceive, explain, and cope with the illness. ${ }^{9,10}$ The confluence of these 2 perspectives encompasses the lived experience of illness, its associated cultural and social categories (spiritual, ethnic, folk, and family beliefs), and their interactions with the psychobiological processes of chronic pathology. ${ }^{10}$ Shared understandings among health professionals, patients, and families about the meaning of illness, suffering, recovery, and death become central to chronic care. ${ }^{11}$

Second, unlike acute illnesses, chronic illnesses bring a dynamic complexity inherent in their lengthy and multifactorial nature. Caused by irreversible pathologic alterations, chronic illnesses often leave residual disability and require intermittent periods of care and complex treatment. ${ }^{12-16}$ Changing patterns of illness are created from the interaction of the disease, its consequences, and the social context-all dynamic in nature, and requiring continual monitoring and complex management.

Together, these characteristics help specify 2 features of chronic care activities: (1) they occur at the confluence of processes that are rooted in the biological, psychosocial, and cultural realms of human experience; as such, they raise issues of shared meanings and mutual dependencies among the participants; and (2) they weave together the developmental threads of chronic illness, of patient and family, and of the health care team. ${ }^{17}$ Chronic care appears as a collective enterprise, mobile, changing, and riddled with renewed instabilities that reflect variable qualitative and quantitative differences in how diseases are manifested over time and in how patients, family members, and health professionals respond to them. How then can we integrate these features into our conception of chronic care design and practice?

\section{INTEGRATING CHRONIC CARE DESIGN AND PRACTICE}

Two perspectives are necessary. Both draw on approaches in human ecology. ${ }^{18}$ The first, a communal view, recognizes the interdependent nature of illness management activities. The second, a dynamic view, recognizes the mobile and shifting qualities of illness experiences.

\section{The Communal View of Chronic Care}

In an ecosystemic approach, chronic care is a communal engagement of its participants in a set of recurring activities that are part of the same human enterprise: preserving life, establishing viable relationships with the environment, surviving together. ${ }^{18}$ Chronic care in this view is a communal adaptive system, an association of specific individuals who through an organization of their resources, differentiated activities, and skills, act as a unit to preserve, improve, and expand life to the maximum attainable under the prevailing opportunities and constraints of their environments (physical, biological, homes, workplaces, hospitals, clinics). ${ }^{18-21}$

In this ecosystem, several linkages are created among the participants' activities and between specific niches they occupy. ${ }^{18}$ As Figure 1 indicates, encounters between the patient, family members, and health professionals bring together multiple cognitive and emotional representations of the illness, multiple behavioral modalities, and multiple skills that underlie behavior performance. ${ }^{22,23}$ Health professionals provide knowledge and expertise in health care. Patients provide selfcare skills and the physiologic energy to accomplish self-care activities. ${ }^{8,24}$ Family members also invest time, energy, emotions, money, and other resources into coping with the illness. ${ }^{25,26}$ Chronic care appears as a more or less effective arrangement of mutual dependencies and collaborative efforts, a network of communication and relationship ties among patients, family members, and health professionals, designed to achieve common health goals. ${ }^{18,21,27}$

An important corollary of the communal view is that the encounters of the patient, family, and health professionals are also those of a learning community - a group of individuals who through language and conversations negotiate meanings and learn about the illness, about each other, and about themselves. ${ }^{28,29}$ Indeed, the participants in chronic care activities are purposeful human beings whose behavior is shaped by the ideas, meanings, and interpretations that they have of themselves and their environments. ${ }^{30,31}$ Because chronic illness changes how patients and families perceive themselves and what they can do, they also develop new meanings and new ways of responding to their environments, including their encounters with health professionals. ${ }^{28,32}$ In turn, health professionals learn from the patient and family, and from the collective work and knowledge that are triggered and nurtured by the clinical encounters. Insights from complexity theory reinforce this view as they indicate that learning can emerge from the interactions and enacted differences among adaptive agents. ${ }^{33-37}$ In their conversations, for example, health professionals, patients, and family members may have differences in opinion, beliefs, behaviors, knowledge, and ways of thinking. As a result of these differences, learning-in the form of shifts of understanding and novel patterns 


\section{Figure 1. Interactions of the patient, family members, and health professionals:} the encounter of multiple competencies.

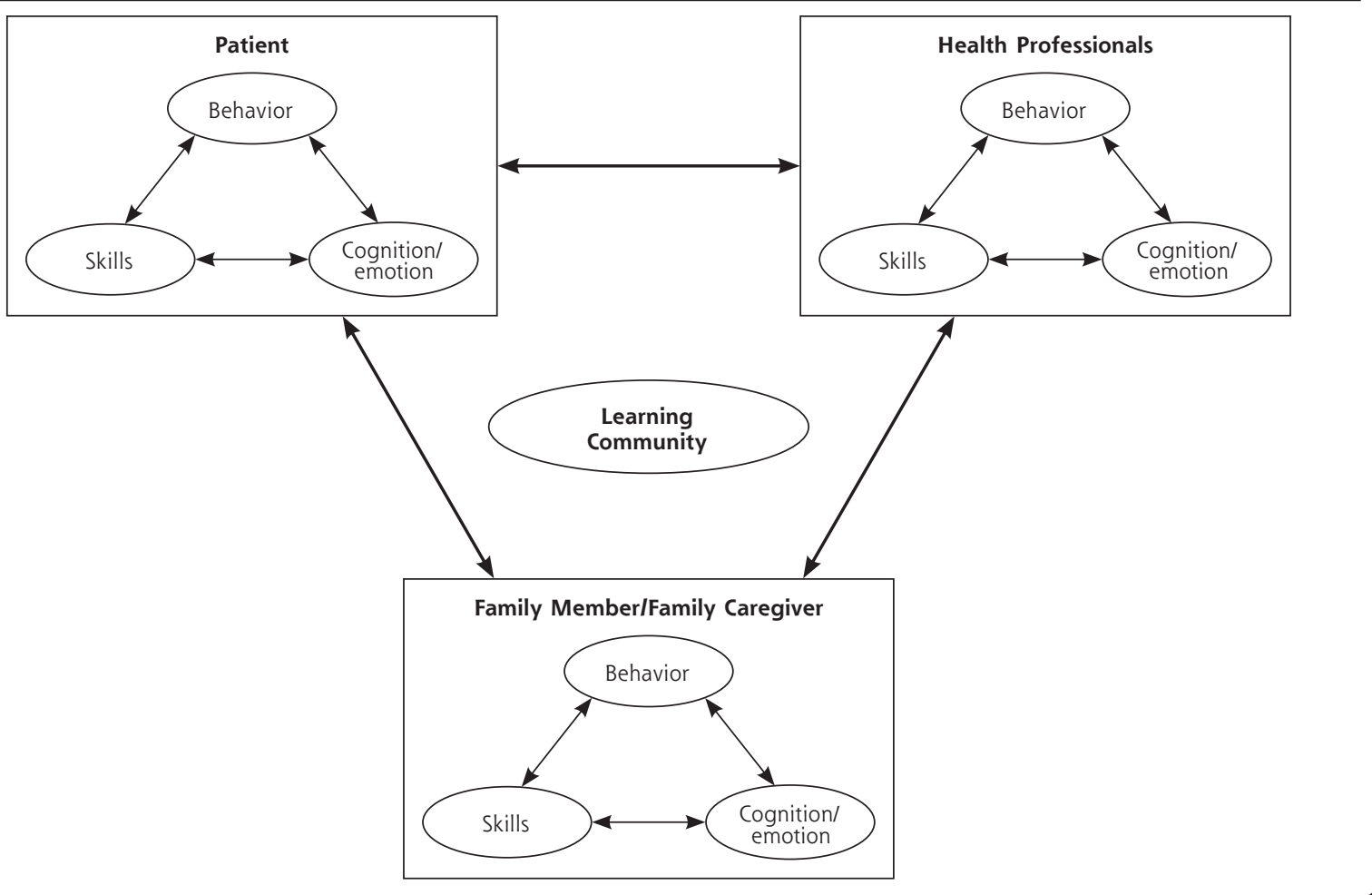

of thoughts, emotions, and behaviors (eg, conflicts, rules, prescribing behaviors) — can emerge and spread through subsequent conversations and interactions among the participants. ${ }^{33,37}$

A communal view therefore highlights the need to integrate the identities, skills, and resources of all the participants. ${ }^{28,29}$ It also underlines the cocreative nature of the response to chronic illness. ${ }^{18,34-37}$ What and how the participants learn in the course of the illness become central to chronic care. ${ }^{28,29,36}$

\section{The Dynamic View of Chronic Care}

In the dynamic view, we recognize the episodic and changing nature of the interdependencies among the participants. Chronic care requires ongoing adjustments marked by some phases when the patient is selfreliant and other phases when he or she is dependent on health professionals. ${ }^{38}$ These phases reflect the mobile nature of the locus of control over change. ${ }^{39}$ Managing this shifting reality requires flexible designs that can match the variable patterns of illness and their associated demands and resources.

In the dynamic view, we also recognize the patterned influence of time on chronic care activities. Time in chronic care shifts away from single events to recurring episodes, and from a linear view of past, present, and future to a variable integration of specific recurring activities and durations at the level of the patient, family, and health professionals. In other words, chronic care time has rhythm, and temporal rhythms must be included in the context of illness management. For health professionals, many standing patterns of behavior-blood sampling, radiographic screening, physician-patient meeting-have more or less predictable delays and occur only at certain times of the day, week, or month. ${ }^{26,40,41}$ For the patient and family, chronic care activities are also intermittent-their temporal spacing being regulated by the recurring needs for food, rest, and other daily needs - and only a subset of these activities involves the interaction of the patient with health professionals. ${ }^{18,32,42}$ Considering time also introduces a historical dimension through which these activities are understood in terms of the patient's and family's unique history with illness, developmental issues, expectations, resources, and vulnerabilities at different life stages. ${ }^{32}$

A dynamic view of chronic care therefore draws attention to the unfolding of illness management activities over time and to the need to engage the illness at specific time points or recurring time intervals along its lines of deployment-specific time phases that have the potential for important qualitative or quantitative change in the experience of the participants. ${ }^{17,32}$ 


\section{Characteristics of the Ecosystemic Approach}

In summary, an ecosystemic approach to chronic care highlights 3 units of analysis: the group of participants in care activities, their environments (biological, psychosocial, health care organization, family unit), and their adaptive response to chronic illness. What takes primacy in this triad is the adaptive component: the evolving arrangements of mutual dependencies and linkages among the participants and their environments. Effective arrangements of these linkages allow the participants to act as a unit, with shared goals, shared meaning and learning, mutual awareness and understanding of the contributions of each participant (representations, emotions, skills, behaviors), and welltimed communications. Three characteristics of this adaptive ecosystem are essential to chronic care design and practice: it is spread across and beyond the health care organization to include the patient and family as necessary participants; it has rhythm; and it is fluidits specific structure and function emerging from the demands of the illness, the available resources to meet them, and the evolving encounters of the participants.

\section{IMPLICATIONS FOR CHRONIC CARE DESIGN}

Based on the preceding discussion, chronic care design must support community development, emergent learning, and the coordination of efforts within identifiable constraints, resources, and rhythms.

\section{Designing for Community}

There is much to know about the requirements of a design that recognizes the patient and family as necessary participants in the care team. ${ }^{26}$ The challenges of designing for community go beyond giving the patient and family a voice in decisions. ${ }^{26,43-45}$ They are those of negotiating meanings not just in conflicting multicultural encounters, but also in the clashing of the narrative logic of the experience of illness and the

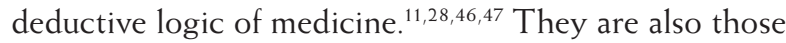
of dispersed communities (eg, health care organization, family unit), time, and fluctuating demands of the illness with varying dependence on health professionals. ${ }^{38,39}$ The challenges also reside in how to organize the relationships among the participants: how to recognize, coordinate, value, and leverage their engagement to the health care organization. ${ }^{48}$ An example of a useful area of investigation is the architectural and technological design of the spaces wherein the encounters among patient, family, and health professionals occur. ${ }^{28,48,49}$

\section{Designing for Emergent Learning and Practice} Chronic care activities evolve over time with potentially changing goals. ${ }^{26,42}$ Central to this adaptive sys- tem is the ability to detect changes through continual monitoring, and to use those changes as feedback that activates relevant strategies_changing roles for the patient, family members, or health professionals, developing or introducing new skills into the group. ${ }^{26}$ Learning in chronic care is then better conceived in terms of the emergent events and collaborative tasks that structure chronic care. ${ }^{4}$

The emergent nature of chronic care activities challenges the planned didactic strategies that follow evidence-based guidelines. Designing for emergent learning and practice is more about the definition of goals, constraints, and coordination of resources than the detailed formulation of fixed competences and places for learning or practice. Examples of constraints/ resources include patients' access to resources that support self-management or the physiologic factors that impinge on their energy to manage the illness. Other examples include the available technology, the relevant mix of professionals, the locations for collaborative practice (health care organization, family unit, or both), and the schedules, roles, potential partners, and financial arrangements within the practice and the family unit. ${ }^{39}$

Designing for emergent learning and practice would then leave ample space for imagination, improvisation, and creative adjustment to the more or less predictable experiences of illness. To be anchored in the communal engagement of practice, imagination and improvisation would rely not only on dry runs and simulations, periodic review sessions, and keeping up with new technologies and research literature, but also on the development of an organizational culture that favors a sense of community, trust, and openness to experimentation and discovery. ${ }^{17,28,32,50,51}$ Ongoing experiences with process change methods such as the Plan, Do, Study, Act (PDSA) cycles suggest that the "try it and see" attitude, combined with group processes and leverage on the health care organization through its senior leaders, is an essential element of successful collaboratives. ${ }^{52}$ Models of communities of practice are also promising for the chronic care context for their potential to integrate learning and practice. ${ }^{48,53}$ Communities of practice can provide an effective social context for reflection on collective experience during and outside of the clinical encounters, and can help develop and refine the knowledge used in practice iteratively. ${ }^{28,50,54}$

\section{RECOMMENDATIONS FOR CLINICAL PRACTICE}

The following recommendations can serve as a guide for designing for community and emergent learning and practice. 
1. Develop your "village square" by assembling team members around clinical tasks and social situations. Create lively gathering places where the participants can get to know each other and develop a sense of belonging to a larger community. The village square can take different forms-Web-based forums, lively water cooler areas, workshops, and group meetings for patients to discuss their self-management strategies. The goal here is to deepen the connections with patients, their families, and team members as a group of people who have agency, a specific history with illness, and who live a particular life. ${ }^{39,55}$

2. Elicit and foster participation. Make trust and compassion strategic requirements of chronic care, encourage self-reporting of mistakes, and target your interventions to relationships, not solely to individual patients or team members. For example, for diabetic patients to change their diet, their connection to their family members in relation to food selection, preparation, and eating schedule may also need to change; for team members to improve their collective performance, they must understand how they depend on each other. $48,56,57$

3. Make the patient's and family members' perceptions and emotions an essential thrust of clinical efforts. ${ }^{58}$ Sincere emotional connections are the basis for trust, empathy, and insightful compassion that can help anticipate the confusion and the potential for learning that patients and families bring to the clinical encounters at different stages of the illness. ${ }^{56}$ What questions will they be asking? What skills will they require? How much do we need to know about them, and how much do they need to know about the professional team? How will their thinking or emotions mesh or clash with professionals' thinking and emotions?

4. Ask not only what you can do for your patients, but also what the patients and families can do for themselves and for your clinical practice. Make cocreation of care plans a strategic requirement of chronic care; patients and families are primary care's best learning asset as they trigger specific domains of knowledge that become focal points for connecting and organizing the resources of all involved. ${ }^{28}$

5. Link the business value (caring for patients) to the knowledge value ${ }^{48}$ and knit a varied quilt. Identify key activities depending on the illness, analyze them in terms of critical knowledge domains, and identify who among the participants needs this knowledge..$^{48}$ Connect people with different expertise, and leverage the accumulation of experience by making visible both their explicit and tacit knowledge: organize their work around common tasks, record their conversations, collect and communicate their failure and success stories. ${ }^{37}$

6. Learn more about narrative medicine. Know how to listen to stories and how to tell them..$^{37,46}$
7. Anticipate accumulation and decline on different accounts. Schedule visits around specific phases of the illness timeline to assess skills, self-regulation, coping behaviors, and resources; schedule assessments for all the participants, not just for the patient and family. 17,36

8. Think in terms of incremental change. Think of small experiments to test and implement change and learn from variation. ${ }^{59}$ Plan also for repeated measures of implementation and outcome; data accumulated over time can reveal the appropriate timing of interventions. ${ }^{50,60}$

9. Problem-solve, yet be flexible and goal oriented. ${ }^{21}$ Who is responsible for change? Is the relevant information at the level of the patient, family, health professionals, or the larger social community? ${ }^{39} \mathrm{Com}$ prehensive chronic care goals are then defined as target values at different levels of the ecosystem of illness management including the biological, psychological, familial, and social realms. . $2,61,62$

10. Make a habit of reflection time. Reflection can be organized around broad phases of the illness timeline, such as a 4 -stages axis including prediagnosis, diagnosis/treatment, recovery/disability, and death. ${ }^{32}$ Each of the phases represents a turning point to important change in the illness, its demands, and the resources to meet them. Reflection can also be done before, during, and after the visit, and can, for example, facilitate the production of visit summaries for patients. ${ }^{63}$

11. Keep a record of your learning process. ${ }^{53}$

12. Think longitudinally, but remember the circular nature of time. Temporal rhythms provide the beat that influences the pace of what patients do to manage their illness, with whom, when, and where they are able to do it. Create an effective rhythm by adjusting the frequencies of communications among the participants to facilitate collaborative practices, coordinated engagements in care activities, and the development of a sense of community. ${ }^{39,48}$

13. Challenge assumptions once in a while. Keep asking, why do we do this in this way? ${ }^{64}$

\section{CONCLUSION}

Design for acute care, with its standardization of process, may be likened to that of an ice cube formed in the mold of a cubic slot where water is frozen into a pregiven form. In contrast, design for chronic care is better compared with that of a snowflake that forms itself in a streaming space by tapping into the useful flows of gravity, wind, humidity, dusts, and chemical gradients. As much as each snowflake differs from any other, each patient lives a unique illness experience that generates a unique set of interactions with health 
professionals. For patients, the streaming space that shapes chronic care includes not only their peculiar list of physiologic constraints tied to specific diseases and comorbidities, but also their need for food and rest, individual preferences, available resources, and uncertain everyday decisions. ${ }^{8}$ For health professionals, chronic care is shaped not only by their expertise, but also by their intuition and creativity to expand their competence by integrating the patient's comorbidities, family and work problems, conflicting schedules, economic resources, and constraints. ${ }^{65}$

The shifts required to implement this understanding represent a cultural change. From an ethos of standardization and prefabricated structures, the move is to a streaming and tracking ethos in which health professionals develop new ways to recognize, value, and manage the communal response to illness; new ways to document and learn from the changing nature of illness experiences; and new ways to cultivate openness, trust, and communal engagement that facilitate collective learning and help sharpen the participants' responsiveness to the emergent-all essential skills for those who want to foster and enjoy their relationship with each patient. ${ }^{28,48,50,65}$

To read or post commentaries in response to this article, see it online at http://www.annfammed.org/cgi/content/full/5/3/263.

Key words: Chronic illness; health professionals; ecosystem; family; learning community; complexity; health care delivery/health services research; psychosocial factors; systems theory; models, theoretical

Submitted February 22, 2006; submitted, revised, October 17, 2006; accepted October 30, 2006.

Funding support: This work has benefited from support from the Department of Family Medicine at the University of Sherbrooke, the Fondation Relève Médecine 2000, the Department of Family Medicine at the University of Montreal, and the Groupe de Recherche Interdisciplinaire en Santé.

Acknowledgments: I am grateful to William Miller for his helpful comments on an earlier version of this manuscript and to Robert Thivierge for directing me to some of the best readings about knowledge management and learning in clinical practice. Special thanks go to Paule Lebel for many stimulating conversations on the topic of medical education. I am also thankful to Martin Fortin, Sharon Hatcher, and Catherine Hudon for their supportive comments.

\section{References}

1. Davis RM, Wagner EG, Groves T. Advances in managing chronic disease. Research, performance measurement, and quality improvement are key. BMJ. 2000;320(7234):525-526.

2. Weingarten SR, Henning JM, Badamgarav $E_{\text {, et al. Interventions }}$ used in disease management programmes for patients with chronic illness - which ones work? Meta-analysis of published reports. BMJ. 2002;325(7370):925.

3. Wagner EH, Groves T. Care for chronic diseases. BMJ. 2002;325 (7370):913-914.
4. Rothman AA, Wagner EH. Chronic illness management: what is the role of primary care? Ann Intern Med. 2003;138(3):256-261.

5. World Health Organization. Innovative Care for Chronic Conditions. Building Blocks for Action. Global Report. Geneva, Switzerland: World Health Organization; 2002.

6. Grumbach K. Chronic illness, comorbidities, and the need for medical generalism. Ann Fam Med. 2003;1(1):4-7.

7. Kane RL. The chronic care paradox. J Aging Soc Policy. 2000;11(2-3): 107-114.

8. Thorne S, Paterson B, Russell C. The structure of everyday self-care decision making in chronic illness. Qual Health Res. 2003;13(10):1337-1352.

9. Ellrodt G, Cook DJ, Lee J, et al. Evidence-based disease management. JAMA. 1997;278(20):1687-1692.

10. Kleinman A. The Illness Narratives. Suffering, Healing and the Human Condition. New York, NY: Basic Books; 1988.

11. Chrisman N, Kleinman A. Popular health care, social networks, and cultural meanings: the orientation of medical anthropology. In: Mechanic D, ed. Handbook of Health, Health Care, and the Health Professions. New York, NY: Free Press; 1983:569-590.

12. Salzman C. Medication compliance in the elderly. J Clin Psychiatry. 1995;56(Suppl 1):18-22; discussion 23.

13. Cooper JK, Love DW, Raffoul PR. Intentional prescription nonadherence (noncompliance) by the elderly. J Am Geriatr Soc. 1982;30(5):329-333.

14. Helgeson V. The onset of chronic illness: its effect on the patientspouse relationship. J Soc Clin Psychol. 1994;12:406-428.

15. Brand FN, Smith RT, Brand PA. Effect of economic barriers to medical care on patients' noncompliance. Public Health Rep. 1977;92(1):72-78.

16. Hoffman C, Rice D, Sung HY. Persons with chronic conditions. Their prevalence and costs. JAMA. 1996;276(18):1473-1479.

17. Rolland J. Toward a psychosocial typology of chronic and lifethreatening illness. Fam Syst Med. 1984;3(2):245-262.

18. Hawley A. Human Ecology: A Theoretical Essay. Chicago, Ill: University of Chicago Press; 1986.

19. Buetow SA. To care is to coprovide. Ann Fam Med. 2005;3(6):553-555.

20. Simon $\mathrm{H}$. The architecture of complexity. Proc Am Philos Soc. 1962;106(6):467-482.

21. Mold JW, Blake GH, Becker LA. Goal-oriented medical care. Fam Med. 1991;23(1):46-51.

22. Grumbach K, Bodenheimer T. Can health care teams improve primary care practice? JAMA. 2004;291(10):1246-1251

23. Barlow J, Wright C, Sheasby J, Turner A, Hainsworth J. Self-management approaches for people with chronic conditions: a review. Patient Educ Couns. 2002;48(2):177-187.

24. Lamb J, Borycki E, Marciniuk D. Energy conservation and fatigue. In: Bourbeau J, Nault D, Borycki E, eds. Comprehensive Management of Chronic Obstructive Pulmonary Disease. Hamilton, Ontario: BC Decker Inc; 2002:171-183.

25. Fisher L, Ransom DC, Terry HE, Burge S. The California Family Health Project: IV. Family structure/organization and adult health. Fam Process. 1992;31(4):399-419.

26. Christianson J, Taylor R, Knutson D. Restructuring Chronic Illness Management. Best Practices and Innovations in Team-Based Treatment. 1st ed. San Francisco, Calif: Jossey-Bass; 1998.

27. Gittell J. Organizing work to support relational coordination. Int J Hum Resource Manage. 2005;11(3):517-539.

28. Wenger E. Communities of Practice: Learning, Meaning, and Identity. New York, NY: Cambridge University Press; 1998.

29. Adams S, Pill R, Jones A. Medication, chronic illness and identity: the perspective of people with asthma. Soc Sci Med. 1997;45(2):189-201. 
30. Tsoukas $\mathrm{H}$. Introduction: from social engineering to reflective action in organizational behaviour. In: Tsoukas $\mathrm{H}$, ed. New Thinking in Organizational Behaviour: From Social Engineering to Reflective Action. Oxford, England: Butterworth-Heinemann Ltd; 1994:1-22.

31. Clark N, Becker M, Janz N, et al. Self-management of chronic disease by older adults. A review and questions for research. J Aging Health. 1991;3(1):3-27.

32. Leventhal $H$, Leventhal $E$, Van Nguyen $T$. Reactions of families to illness: theoretical models and perspectives. In: Turk D, ed. Health, Illness, and Families. New York, NY: John Wiley \& Sons; 1985.

33. Wilson T, Holt T, Greenhalgh T. Complexity science: complexity and clinical care. BMJ. 2001;323(7314):685-688.

34. Plsek PE, Greenhalgh T. Complexity science: the challenge of complexity in health care. BMJ. 2001;323(7313):625-628.

35. Miller WL, Crabtree BF, McDaniel R, Stange KC. Understanding change in primary care practice using complexity theory. J Fam Pract. 1998;46(5):369-376.

36. Fraser SW, Greenhalgh T. Coping with complexity: educating for capability. BMJ. 2001;323(7316):799-803

37. Donaldson A, Lank E, Maher J. Connecting through communities: how a voluntary organization is influencing health care policy and practice. J Change Manage. 2005;5(1):71-86.

38. Gallagher E. Chronic illness management. A focus for future research applications. In: Gochman D, ed. Health Behavior. Emerging Research Perspectives. New York, NY: Plenum Press; 1988:397-407.

39. Seaburn D, Lorenz A, Gunn WJ. Models of Collaboration. A Guide for Mental Health Professionals Working With Health Care Practitioners. 1st ed. New York, NY: Basic Books, HarperCollins Publishers, Inc; 1996

40. Barker R. Ecological Psychology. Palo Alto, Calif: Stanford University Press; 1968.

41. Locock L. Healthcare redesign: meaning, origins and application. Qual Saf Health Care. 2003;12(1):53-57.

42. Nerenz D, Leventhal H. Self-regulation theory in chronic illness. In: Burish T, Bradley L, eds. Coping With Chronic Disease: Research and Applications. New York, NY: Academy Press; 1983.

43. Von Korff M, Gruman J, Schaefer J, Curry SJ, Wagner EH. Collaborative management of chronic illness. Ann Intern Med. 1997;127(12):1097-1102.

44. Bodenheimer T, Wagner EH, Grumbach K. Improving primary care for patients with chronic illness. JAMA. 2002;288(14):1775-1779.

45. Bodenheimer T, Wagner EH, Grumbach K. Improving primary care for patients with chronic illness: the chronic care model, Part 2. JAMA. 2002;288(15):1909-1914.

46. Charon R. Narrative and medicine. N Engl J Med. 2004;350(9):862-864.

47. Thorne SE, Harris SR, Mahoney K, Con A, McGuinness L. The context of health care communication in chronic illness. Patient Educ Couns. 2004;54(3):299-306.
48. Wenger E, McDermott R, Snyder W. Cultivating Communities of Practice: A Guide to Managing Knowledge. Boston, Mass: Harvard Business School Press; 2002.

49. Nadler D, Gerstein M, Shaw R. Organizational Architecture: Designs for Changing Organizations. San Francisco, Calif: Jossey-Bass; 1992.

50. Bohmer RM, Edmondson AC. Organizational learning in health care. Health Forum J. 2001;44(2):32-35.

51. Leventhal H, Leventhal E, Cameron L. Representations, procedures, and affect in illness self-regulation: a perceptual-cognitive model In: Baum A, Revenson T, Singer J, eds. Perceptions of Health and Illness: Current Research and Applications. Mahwah, NJ: Lawrence Erlbaum; 2001:19-48.

52. Wagner E, Glasgow R, Davis C. Quality improvement in chronic illness care: a collaborative approach. J Qual Improve. 2001;27:63-80.

53. Parboosingh JT. Physician communities of practice: where learning and practice are inseparable. J Contin Educ Health Prof. 2002;22(4):230-236

54. Schon D. Teaching artistry through reflection-in-action. In: Tsoukas $\mathrm{H}$, ed. New Thinking in Organizational Behaviour: From Social Engineering to Reflective Action. Oxford, England: Butterworth-Heinemann Ltd; 1994:1-22.

55. Liaschenko J. Knowing the patient? In: Thorne S, Hayes V, eds. Nursing Praxis. Knowledge and Action. Thousand Oaks, Calif: Sage Publications, Inc: 1997:23-38.

56. Epstein RM. Mindful practice. JAMA. 1999;282(9):833-839.

57. Weick K, Sutcliffe K. Managing the Unexpected. 1st ed. San Francisco, Calif: John Wiley \& Sons, Inc; 2001.

58. Malterud $\mathrm{K}$, Hollnagel $\mathrm{H}$. The doctor who cried: a qualitative study about the doctor's vulnerability. Ann Fam Med. 2005;3(4):348-352.

59. Berwick DM. Developing and testing changes in delivery of care. Ann Intern Med. 1998;128(8):651-656.

60. Classen DC, Evans RS, Pestotnik SL, et al. The timing of prophylactic administration of antibiotics and the risk of surgical-wound infection. N Engl J Med. 1992;326(5):281-286.

61. Miller J. Living Systems. New York, NY: McGraw-Hill; 1978.

62. Nakagawa-Kogan H, Garber A, Jarrett M, Egan KJ, Hendershot S. Self-management of hypertension: predictors of success in diastolic blood pressure reduction. Res Nurs Health. 1988;11(2):105-115.

63. Solberg LI, Hroscikoski MC, Sperl-Hillen JM, Harper PG, Crabtree BF. Transforming medical care: case study of an exemplary, small medical group. Ann Fam Med. 2006;4(2):109-116.

64. Plsek P. Innovative thinking for the improvement of medical systems. Ann Intern Med. 1999;131(6):438-444.

65. Hankey TL. What good family doctors really do [electronic letter]. Available at: http://www.annfammed.org/cgi/eletters/3/3/209\#2128. Accessed: 11 October 2006. 